\title{
The Prognostic Significance of the Metastatic Lymph Node Ratio versus the Number of Affected Lymph Nodes in Patients with Colorectal Cancer Stage III Undergoing Potentially Curative Surgery
}

\author{
AHMED S.A. ABDUL-SAMAD, M.Sc.; MOSTAFA A. SOLIMAN, M.D.; MAMDOH H. HAGGAG, M.D. and \\ TAREK O. HEGAZY, M.D.
}

The Department of General Surgery, Faculty of Medicine, Cairo University

\begin{abstract}
Background: Many investigators have questioned the prognostic power of the TNM system in the prognosis of colorectal cancer because of the possibility of stage migration, and have proposed alternative prognostic methods; one of those is the lymph node ratio.
\end{abstract}

Aim of Work: The objective of this study is to compare the prognostic significance of the LNR with the absolute number of affected lymph nodes for resected colorectal adenocarcinoma stage III regarding overall and disease specific survival.

Patients and Methods: 55 patients with colorectal cancer stage III who underwent curative surgery were enrolled in a retrospective cohort study reviewing their medical charts from Medical Oncology Department between January 2005 and December 2006, and their five years follow-up period regarding local recurrence, metastasis and survival.

Results: The mean follow-up time was $55.1 \pm 18$ months (range 6-72, median 60 months). During this time period, 12 $(21.8 \%)$ patients died of disease, 20 (36.4\%) patients developed local recurrence or metastasis. Overall Survival (OS) was $90.9 \%, 85.5 \%, 78.2 \%$ at $1.5,3,5$ years respectively. Disease Specific Survival (DSS) was $90.9 \%, 74.5 \%, 63.6 \%$ at $1.5,3$, 5 years respectively.

Five year overall survival rates was significantly worse in colorectal cancers with LNR $>40 \%$ ( $p$-value $<0.01$, hazard ratio $0.022,95 \%$ CI $0.003-0.17)$ and also worse 5 year disease specific survival ( $p$-value $<0.01$, hazard ratio $0.182,95 \% \mathrm{CI}$ $0.075-0.44)$. Total $\mathrm{LN} \leq 11$ and positive number of LNs $>4$ showed significant worsening in the 5 year DSS only ( $p$-value $<0.05$, hazard ratio $2.8,95 \%$ CI $1.025-7.7)$ vs. ( $p$-value $<0.05$, hazard ratio $0.32,95 \%$ CI $0.13-0.8$ ) respectively.

Conclusion: LNR was a robust prognostic indicator for node-positive colon cancers undergoing curative surgery. Because this ratio-based staging was demonstrated to reduce stage migration and to aid in identifying high-risk patients,

Correspondence to: Dr. Ahmed S.A. Abdul-Samad, The Department of General Surgery, Faculty of Medicine, Cairo University application of the pLNR improved patient stratification in colorectal cancer and may be considered in future staging systems, it could be proposed as a standard tool for colon cancer staging.

Key Words: Lymph node ratio - Colorectal cancer.

\section{Introduction}

COLORECTAL Cancer (CRC) is the fourth most common cancer and the second-leading cause of cancer deaths overall in men and women in the US [1].

Studies in individuals with colorectal cancer have shown that both disease-free survival and overall survival are correlated with the number of lymph nodes resected [2]. However, the number of lymph nodes identified in the surgical specimen is directly related to the experience of the surgeon performing the resection of the neoplasm, the histopathological technique used to recover them and the experience of the pathologist in identifying them [3]

Few studies have evaluated the LNR in relation to the survival of patients with colorectal cancer [4]. The validity of using the LNR as a variable relating to survival in colorectal cancer patients is still controversial. Some studies have not shown any relationship between the LNR and survival among colorectal cancer patients [5] while others have considered the LNR to be more important than the simple presence of lymph node involvement [6]. Thus, the importance of the LNR as an independent prognostic factor for staging in colorectal cancer still requires better assessment. 


\section{Patients and Methods}

It's a retrospective cohort study, the data were collected from medical charts of 55 patients who underwent curative surgery for colorectal carcinoma stage III at a single institution (the Department of Surgery at Kasr Al-Ainy University Hospital) between January 2005 and December 2006, reviewing their five years follow-up period regarding local recurrence, metastasis and survival.

The prognostic effect of positive Lymph-Node Ratio (pLNR) on patients with stage III Colorectal Cancer (CRC) was evaluated in comparison to the positive number of lymph nodes.

\section{Inclusion criteria:}

All patients with a diagnosis of colorectal adenocarcinoma who are classified as stage III according to 7 th edition of AJCC cancer staging manual [7], and had undergone complete resection of the primary tumour (R0) and lymphadenectomy extended beyond involved nodes at post-operative pathologic examination with negative apical lymph node(s) were considered eligible for the study. Also we included all eligible cases regardless of the number of lymph nodes harvested in this group.

\section{Exclusion criteria:}

Patients with positive macroscopic or microscopic residual tumor $(\mathrm{R} 1, \mathrm{R} 2)$ were excluded from this study, patients who met the Amsterdam criteria for hereditary nonpolyposis colorectal cancer syndrome or patients who have carcinomas associated to inflammatory bowel disease, Sarcomas, lymphomas, and carcinoid tumors were considered ineligible.

\section{Results}

The total number of harvested nodes was (652) LNs mean was $11.85 \pm 7$ (range 3-30, median 10 nodes). In 32 patients $(58.2 \%)$ resected LNs was less than 12 and in 23 patients $(41.8 \%)$ resected LNs was 12 or more.

When stratifying for the parameter $\mathrm{N}$ of the TNM staging system, the lymph node ratio ranged from $6.25 \%-50 \%$ (mean $27.6 \pm 12.5$, median 25 ) in 32 patients with $\mathrm{pN} 1$, and from $16 \%-100 \%$ (mean $40.3 \pm 28.2$, median 26) in 17 patients with pN2a, and from $38.4 \%-100 \%$ (mean $68.3 \pm 23.2$, median $71.6)$ in 6 patients with $\mathrm{pN} 2 \mathrm{~b}$.
The mean follow-up time was $55.1 \pm 18$ months (range 6-72, median 60 months). During this time period, $12(21.8 \%)$ patients died of disease, 20 (3 6.4\%) patients developed local recurrence or metastasis. Overall Survival (OS) was 90.9\%, $85.5 \%, 78.2 \%$ at $1.5,3,5$ years respectively. Disease Specific Survival (DSS) was 90.9\%, 74.5\%, $63.6 \%$ at $1.5,3,5$ years respectively.

Five year Overall survival rates was significantly worse in colorectal cancers with LNR $>40 \%$ ( $p$ value $<0.01$, hazard ratio $0.022,95 \%$ CI 0.003 $0.17)$ and also worse 5 year disease specific survival ( $p$-value $<0.01$, hazard ratio $0.182,95 \%$ CI 0.075 $0.44)$. Total $\mathrm{LN} \leq 11$ and positive number of LNs $>4$ showed significant worsening in the 5 year DSS only ( $p$-value $<0.05$, hazard ratio $2.8,95 \%$ CI $1.025-7.7)$ vs. ( $p$-value $<0.05$, hazard ratio 0.32 , 95\% CI 0.13-0.8) respectively. Table (1).

According to this LNR cutoff value (40\%), the hazard ratio for disease-specific survival was 0.18 (95\% CI 0.075-0.44), corresponding to a $47 \%$ increase in the 5-year survival rate in patients showing a low LNR and a $82 \%$ reduction in the estimated relative risk of cancer-related death in this group.

LNR stratification disclosed survival rate discrepancies both in $\mathrm{pN}$ and TNM staging system clearly related to the stage migration phenomenon. In our series, probability of stage migration in the pN staging system might be inferred from the finding that 5-year OS of $40 \%$ for $\mathrm{pN} 1$ group with high LNR was less favorable than that of $90.9 \%$ for $\mathrm{pN} 2 \mathrm{a}$ group with low LNR, also 5-year OS of $33.3 \%$ for $\mathrm{pN} 2 \mathrm{a}$ group with high LNR was less favorable than that of $100 \%$ for $\mathrm{pN} 2 \mathrm{~b}$ group with low LNR.

When stratifying patients according to TNM stage, patients in the less favorable stage (IIIB) and a low LNR $(\leq 40 \%)$ were shown to live much longer than patients in a more favorable stage (IIIA) and a high LNR (>40\%) (96\% vs. 0\%, respectively), also patients in the less favorable stage (IIIC) and a low LNR $(\leq 40 \%)$ were shown to live much longer than patients in a more favorable stage (IIIB) and a high LNR (>40\%) (100\% vs. $42.8 \%$, respectively).

However stage III by itself shows a significant difference in 5 year OS and DSS among groups IIIA, IIIB, IIIC. Thus showing that LNR may identify more homogeneous groups (IIIA, B, C) controlled by the $\mathrm{T}$ stage, thereby reducing the phenomenon of stage migration. 
It was much more evident stratifying patients according to TNM staging system and LNR. Patients categorized in the same stage (i.e., stages IIIA, IIIB, and IIIC) were shown to significantly differ in long-term survival rates when grouped according to LNR stratification.

The number of positive LNs was significantly increased by the increasing number of harvested nodes $(r=0.548, p<0.05)$ patients with $<12$ resected nodes showed a lower number of metastatic nodes compared with patients with 12 or more LNs but

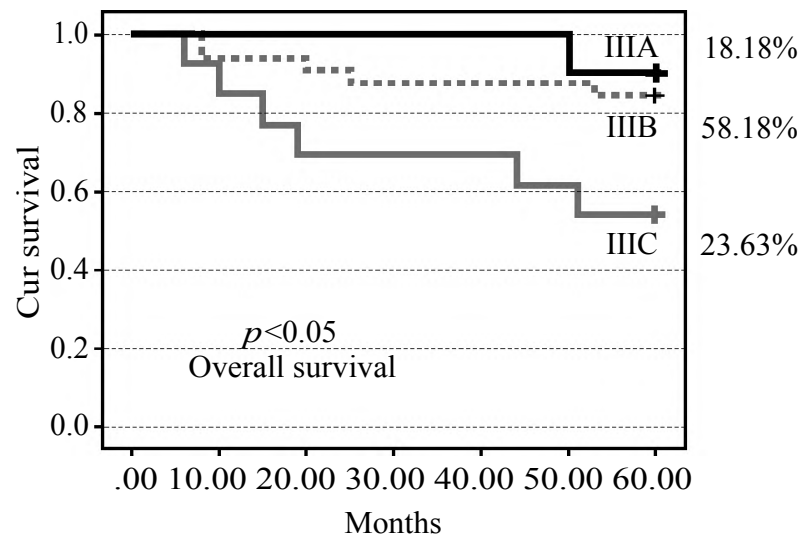

it didn't reach a significance $(p=0.06,95 \%$ CI 0.79 3.9).

LNR increased by $3.88 \%$ as the number of metastatic nodes increased by $1(r=0.524,<0.05)$, and decreased by $0.99 \%$ as the number of total LNs increased by $1(r=0.303, p<0.05)$.

Lymph node ratio has a bigger inverse correlation with overall survival and disease specific survival if compared with positive number of lymph nodes $(r=0.64,-0.55)$ vs. $(r=-0.37,-0.23)$ respectively.

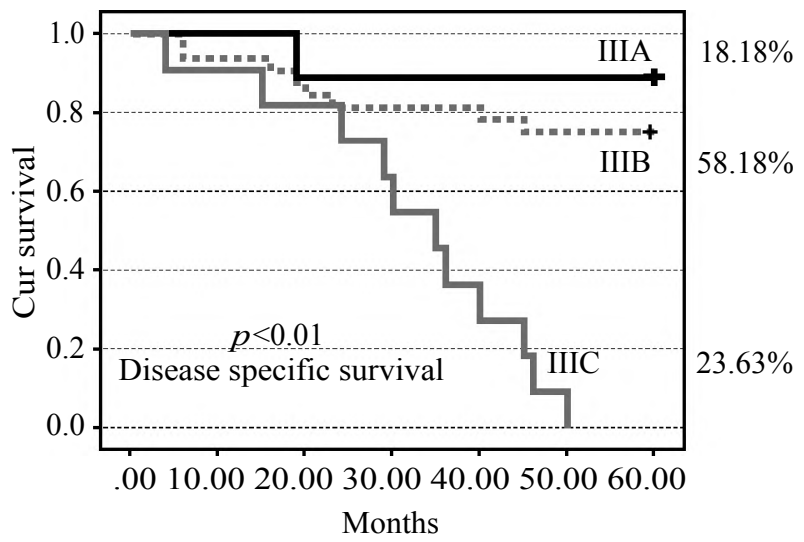

Fig. (1): 5-year survival rates in 55 patients stage III colorectal cancer underwent curative surgery according to TNM stages (IIIA, IIIB, IIIC).
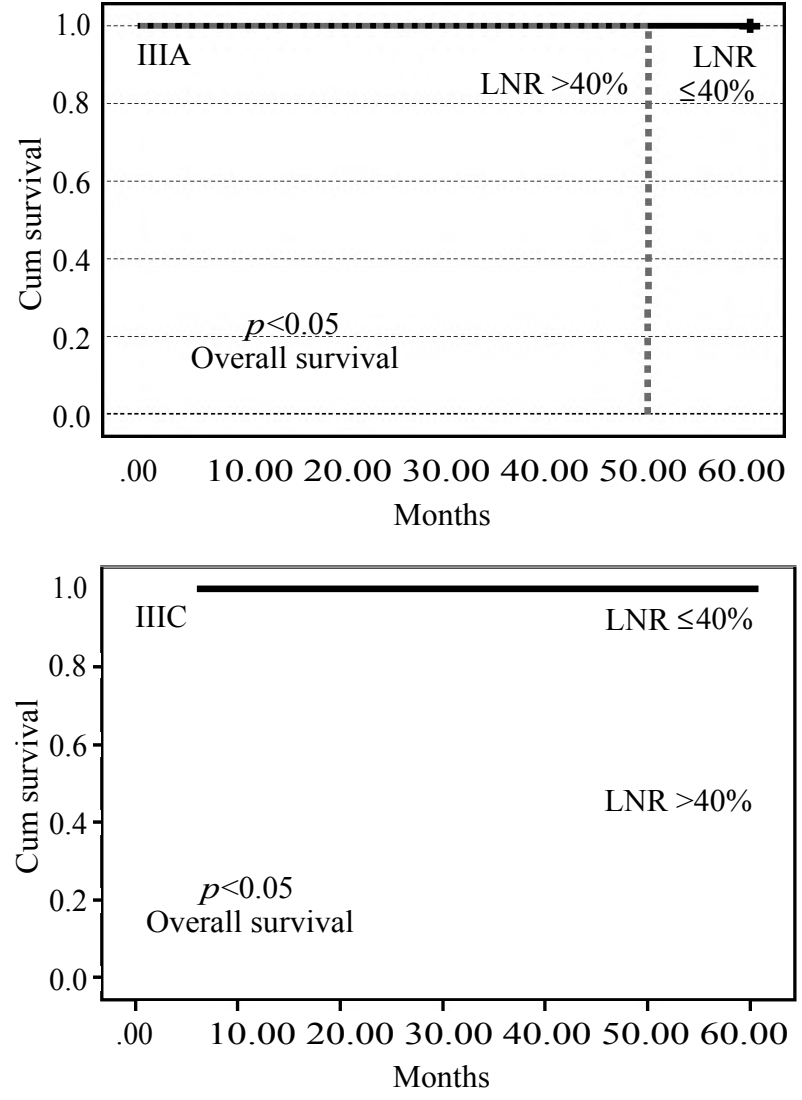

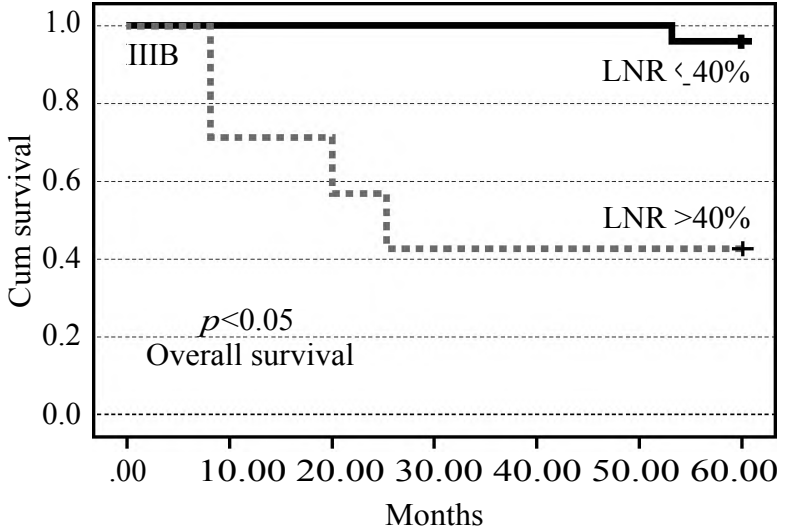

Fig. (2): 5-year overall survival rates in 55 patients stage III colorectal cancer underwent curative surgery according to TNM stage (IIIA, IIIB, IIIC) with LNR stratification: Lymph node ratio (cutoff $>40 \%$ ). 


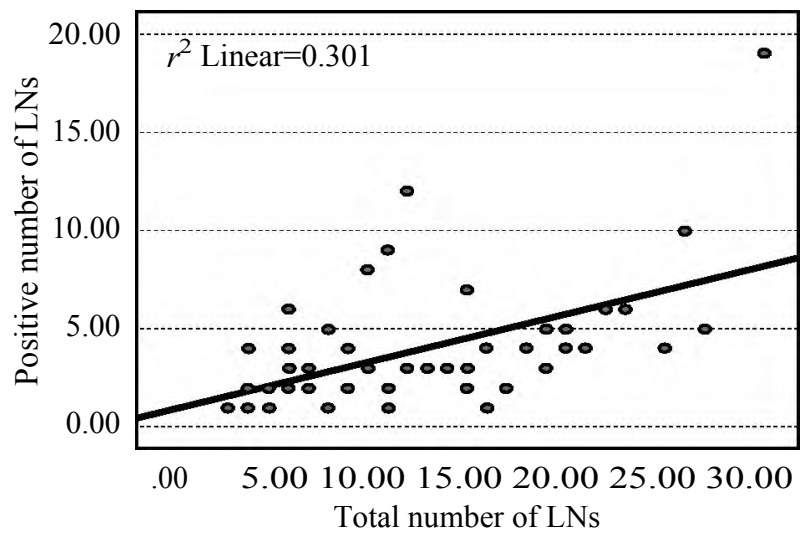

Fig. (3): Linear correlation between the total number of LNs and positive number of LNs $(r=0.548)(p<0.05)$.

Table (1): 5-year survival rates in 55 patients stage III colorectal cancer underwent curative surgery according to cutoff values selected by ROC analysis: Lymph node ratio $(>40 \%)$, positive number of LNs $(>4)$, LNR $(>40 \%)$.

\begin{tabular}{|c|c|c|c|c|c|c|c|c|}
\hline & \multicolumn{4}{|c|}{ Overall survival } & \multicolumn{4}{|c|}{ Disease specific survival } \\
\hline & \multirow{2}{*}{$p$-value } & \multirow{2}{*}{ HR } & \multicolumn{2}{|c|}{$95 \%$ CI HR } & \multirow{2}{*}{$p$-value } & \multirow{2}{*}{ HR } & \multicolumn{2}{|c|}{$95 \%$ CI HR } \\
\hline & & & Lower & Upper & & & Lower & Upper \\
\hline Total LN $<11$ & 0.195 & 2.37 & 0.64 & 8.77 & $<0.05$ & 2.8 & 1.025 & 7.7 \\
\hline$+\mathrm{LN}>4$ & 0.07 & 0.34 & 0.11 & 1.1 & $<0.05$ & 0.32 & 0.13 & 0.8 \\
\hline $\mathrm{LNR}>40 \%$ & $<0.01$ & 0.022 & 0.003 & 0.17 & $<0.01$ & 0.182 & 0.075 & 0.44 \\
\hline
\end{tabular}

Table (2): Survival analysis in 55 patients with stage III colorectal cancer underwent curative surgery according to lymph node stage and the highest accuracy LNR value $(40 \%)$.

\begin{tabular}{|c|c|c|c|c|c|c|c|}
\hline \multirow{2}{*}{ N stage } & \multirow{2}{*}{ Survival } & \multicolumn{2}{|c|}{ LNR } & \multirow{2}{*}{$\begin{array}{l}\text { Hazard } \\
\text { ratio }\end{array}$} & \multicolumn{2}{|c|}{ 95\% CI HR } & \multirow{2}{*}{$\begin{array}{c}p- \\
\text { value }\end{array}$} \\
\hline & & $<40 \%$ & $>40 \%$ & & Lower & Upper & \\
\hline \multirow{2}{*}{ N1 (32) } & OS & $0 / 27-100 \%$ & $3 / 5-40 \%$ & 0.00 & 0.00 & 8.71 & 0.74 \\
\hline & DSS & $7 / 27-74 \%$ & $1 / 5-80 \%$ & 0.89 & 0.11 & 7.25 & 0.91 \\
\hline \multirow[t]{2}{*}{ N2a (17) } & OS & $1 / 11-90.9 \%$ & $4 / 6-33.3 \%$ & 0.081 & 0.009 & 0.74 & $<0.05$ \\
\hline & DSS & $2 / 11-81.8 \%$ & $5 / 6-16.6 \%$ & 0.086 & 0.016 & 0.47 & $<0.01$ \\
\hline \multirow[t]{2}{*}{ N2b (6) } & OS & $0 / 1-100 \%$ & $4 / 5-20 \%$ & 0.032 & 0.00 & 731 & 0.5 \\
\hline & DSS & $1 / 1-0 \%$ & $4 / 5-20 \%$ & 0.024 & 0.00 & 220.2 & 0.422 \\
\hline
\end{tabular}

\section{Discussion}

Current recommendations to examine at least 12-15 LNs are based on an amalgamation of data, the AJCC 7 th edition recommends examination of 12 LNs [7] with the article by Scott and Grace [8] often cited as the source of the recommendation of $12 \mathrm{LNs}$ after fat clearance of the mesorectum. Increased retrieval and evaluation of $\mathrm{LNs}$ does not improve detection of stage III CRC or identify more patients with positive nodes, according to research published in Archives of Surgery [9] however, our results oppose this, showing that the more LNs harvested from the mesentry, the more positive LNs yielded $(r=0.548$, slope $=0.243, p<0.05)$ consistent with results of other researches $[4,10]$.
The large majority of collected and reviewed studies represents a population of node positive (stage III) or mixed (stage II and III) colon cancer patients. In all but one trial [11] the prognostic value of the LNR (other than pathological nodal involvement) was assessed in the presence of possible confounding covariates by Cox multivariate regression. This information is of a paramount importance because it would confirm that LNR is now considered to be an independent prognostic variable that has greater meaning than, and is superior to, the TNM-AJCC classification with regard to disease substaging in stage III disease.

Also selected four positive nodes, perfectly corresponding to the current $\mathrm{pN}$ staging system 
[7], the best LNR value was $40 \%$ to be the most accurate in predicting DSS and OS, higher than other experiences from single institutions [11,12] $(20 \%)$ or larger series [13] (30\%), thus allowing to be confident with this method.

In our study, LNR was a robust prognostic factor for long-term outcome; surviving patients showed significantly lower LNRs than deceased patients, and compared with the number of metastatic and harvested nodes, LNR showed the widest area under the ROC curve confirming its statistical power. As already stated by Wang [14], although questioned by others [12,13], LNR prognostic significance held steady regardless of the number of harvested nodes, suggesting that LNR stratification could obviate a wrong downstaging due to failure to examine an adequate number of nodes.

On multivariate analysis, LNR was shown to be an independent prognostic factor for both disease-specific and disease-free survival rates (both $p<0.01)$. According to this LNR cutoff value ( $40 \%)$, the hazard ratio for disease-specific survival was 0.18 (95\% CI 0.075-0.44), corresponding to a $47 \%$ increase in the 5-year survival rate in patients showing a low LNR and a $82 \%$ reduction in the estimated relative risk of cancer-related death in this group.

Our results are consistent with an analysis by Moug et al., [15], who compared the number of positive LNs and the pLNR in both univariate and multivariate analysis predicting survival rates. pLNR maintained its significance as a prognostic factor in both DSS and OS, whereas the number of positive LNs was not found to be significant in OS $(p=0.07)$.

\section{Conclusion:}

The ratio-based staging (pLNR) of CRC is a more accurate and clinically useful prognostic method than the number of positive LNs resected or the total number of LNs retrieved for predicting the course of patients with stage III CRC.

LNR was a robust prognostic indicator for nodepositive colon cancers undergoing curative surgery. Because this ratio-based staging was demonstrated to reduce stage migration and to aid in identifying high-risk patients, application of the pLNR improved patient stratification in colorectal cancer and could be considered in future staging systems, it may be proposed as a standard tool for colon cancer staging.

\section{References}

1- HOWLADER N., NOONE A.M., KRAPCHO M., GARSHELL J., et al. (eds). Surveillance Epidemiology and End Results. Bethesda MD. SEER Stat Fact Sheets: Colon and Rectum. National Cancer Institute. Updated 2014. http://seer.cancer.gov/statfacts/html/colorect.html Accessed 20th April 2014.

2- CHANG G.J., RODRIGUEZ-BIGAS M.A., SKIBBER J.M., et al.: Lymph node evaluation and survival after curative resection of colon cancer: Systematic review. J. Natl. Cancer Inst.; 99: 433-41, 2007.

3- Le VOYER T.E., SIGURDSON E.R., HANLON A.L., et al.: Colon cancer survival is associated with increasing number of lymph nodes analyzed: A secondary survey of intergroup trial INT-0089. J. Clin. Oncol.; 21: 2912-9, 2003.

4- ELIAS E., MUKHERJI D., FARAJ W., KHALIFE M., DIMASSI H., ELOUBEIDI M., HATTOUM H., ABOU ALFA G.K., SALEH A. and SHAMSEDDINE A.: Lymphnode ratio is an independent prognostic factor in patients with stage III colorectal cancer: A retrospective study from the Middle East. World Journal of Surgical Oncology; 10: 63-72, 2012.

5- TRUFELLI D.C., MIRANDA VDA C., PALOS C.C., et al.: Positive/total dissected lymph nodes ratio as a prognostic factor in colorectal cancer. Rev. Assoc. Med. Bras.; 53: 539-42, 2007.

6- JAGER T., DINNEWITZER A., FITZKA T., WATFAH J. and ÖFNER D.: Impact of Lymph Node Count versus Lymph Node Ratio (LNR) on Survival Analysis in UICC Stage III Colorectal Cancer. Z. Gastroenterol.; 50: 3-12, 2012.

7- EDGE S.B., BYRD D.R., COMPTON C.C., FRITZ A.G., GREENE F.L. and TROTTI A. (eds).: AJCC Cancer Staging Manual (Seventh Edition). Chicago. Springer; 14: 160-73, 2010.

8- SCOTT K.W.M. and GRACE R.H.: Detection of lymph node metastases in colorectal carcinoma before and after fat clearance. Br. J. Surg.; 78: 1165-7, 1989.

9- KUKREJA S.S., ESTEBAN-AGUSTI E., VELASCO J.M. and HIEKEN T.J.: Increased lymph node evaluation with colorectal cancer resection: Does it improve detection of stage III disease. Arch. Surg. Jul.; 144 (7): 612-7, 2009.

10- QIU H.B., ZHANG L.Y., LI Y.F., ZHOU Z.W., KESHARI R.P. and XU R.H.: Ratio of metastatic to resected lymph nodes enhances to predict survival in patients with stage III colorectal cancer. Ann. Surg. Oncol. Jan.; 34: 59-72, 2011.

11- SCHUMACHER P., DINEEN S., BARNETT Jr. C., FLEMING J. and ANTHONY T.: The metastatic lymph node ratio predicts survival in colon cancer. Am. J. Surg. Dec.; 194 (6): 827-31, 2007.

12- LEE H.Y., CHOI H.J., PARK K.J., et al.: Prognostic significance of metastatic lymph node ratio in nodepositive colon carcinoma. Ann. Surg. Oncol. May; 14 (5): 1712-7, 2007.

13- BERGER A.C., SIGURDSON E.R., LeVOYER T., et al.: Colon cancer survival is associated with decreasing ratio of metastatic to examined lymph nodes. J. Clin. Oncol. Dec. 1; 23 (34): 8706-12, 2005. 
14- WANG J., HASSETT J.M., DAYTON M.T. and KULAYLAT M.N.: Lymph node ratio: Role in the staging of node-positive colon cancer. Ann. Surg. Oncol. Jun.; 15 (6): 1600-8, 2008.
15- MOUG S.J., SALDANHA J.D., McGREGOR J.R., BALSITIS M. and DIAMENT R.H.: Positive lymph node retrieval ratio optimises patient staging in colorectal cancer. Br. J. Cancer May 19; 100 (10): 1530-3, 2009.

\section{دراسة الآهمية التتبؤية لنسبة الفدد الليمفاوية الإيجابية

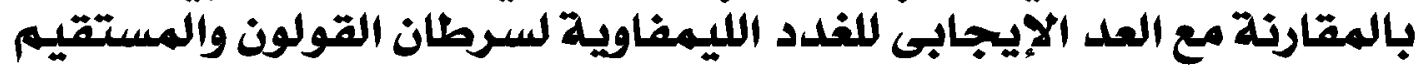

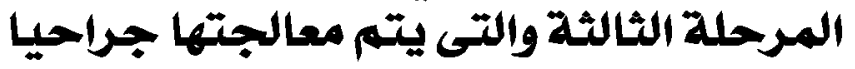

تم مراجعة السجلات الطبية لخمسة وخمسفن مريضا بسرطان القولون والمستقيم المرحلة الثالث الذين يخضعقن لإستئصال الورم السرطاني

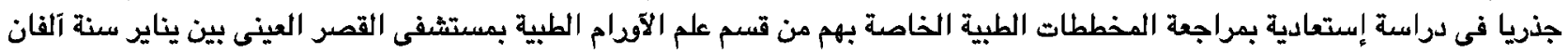

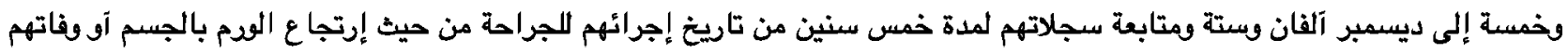

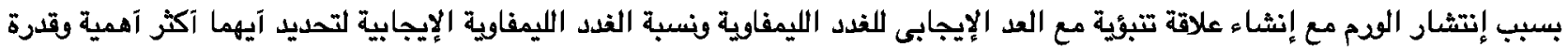
على التنبؤ بالحالة المستقبلية الصحية لهؤلاء المرضى.

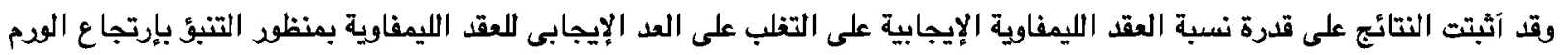

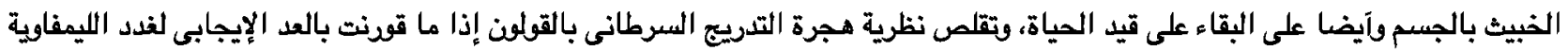

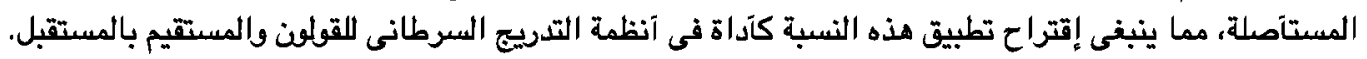

